
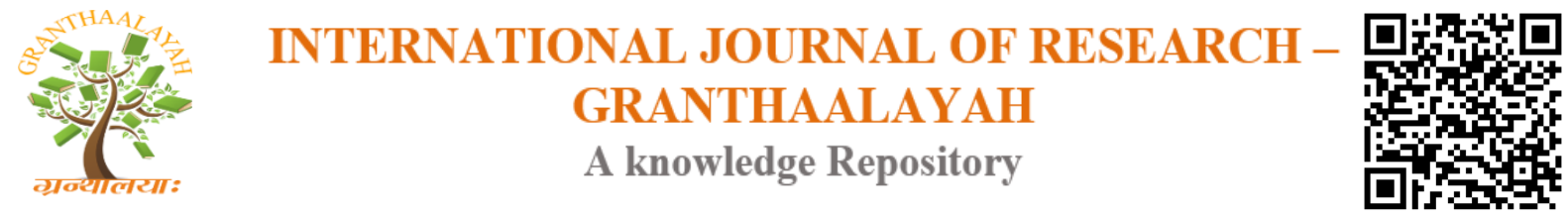

Science

\title{
REDUCTION OF ACTIVE POWER LOSS BY ADAPTIVE CHARGED SYSTEM SEARCH ALGORITHM
}

\author{
Dr.K.Lenin *1 \\ ${ }^{* 1}$ Professor, Department of EEE Prasad V.Potluri Siddhartha Institute of Technology, Kanuru, \\ Vijayawada, Andhra Pradesh -520007, India
}

\begin{abstract}
This paper presents a new optimization algorithm called Adaptive Charged System Search Algorithm (ACA) for solving optimal power problem. Coulomb law from electrostatics and the Newtonian laws of mechanics are forming the basics of the proposed algorithm. Adaptive Charged System Search Algorithm (ACA) is a multi-agent approach in which each agent is a Charged Particle (CP) \& they affect each other based on their fitness values, separation of distances. The quantity of the resultant force is determined by using the electrostatics laws and the quality of the movement is determined using Newtonian mechanics laws. Proposed Adaptive Charged System Search Algorithm (ACA) has been tested in Standard IEEE 57,118 bus systems $\&$ real power loss has been comparatively reduced with voltage profiles are within the limits.
\end{abstract}

Keywords: Optimal Reactive Power; Transmission Loss; Charged Particle; Adaptive Charged System Search Algorithm.

Cite This Article: Dr.K.Lenin. (2017). "REDUCTION OF ACTIVE POWER LOSS BY ADAPTIVE CHARGED SYSTEM SEARCH ALGORITHM." International Journal of Research - Granthaalayah, 5(10), 34-45. 10.29121/granthaalayah.v5.i10.2017.2265.

\section{Introduction}

Optimal reactive power problem plays most important role in the stability of power system operation and control. In this paper the main aspect is to diminish the real power loss and to keep the voltage variables within the limits. Previously many mathematical techniques like gradient method, Newton method, linear programming [4-7] has been utilized to solve the optimal reactive power dispatch problem and those methods have many difficulties in handling inequality constraints. Voltage stability and voltage collapse play an imperative role in power system planning and operation [8]. Recently Evolutionary algorithms like genetic algorithm have been already utilized to solve the reactive power flow problem [9,10].In [11-20] Genetic algorithm, Hybrid differential evolution algorithm, Biogeography Based algorithm, fuzzy based methodology, improved evolutionary programming has been used to solve optimal reactive power flow problem and all the algorithm successfully handled the reactive power problem. The Artificial Bee Colony (ABC) algorithm was introduced by Karaboga [21] as a technical report, 
and then its performance was measured using benchmark optimization functions [22-33]. This paper presents a new optimization algorithm called Adaptive Charged System Search Algorithm (ACA) for solving optimal power problem. Coulomb law from electrostatics and the Newtonian laws of mechanics are forming the basics of the proposed algorithm. Adaptive Charged System Search Algorithm (ACA) is a multi-agent approach in which each agent is a Charged Particle (CP) [34-37] \& they affect each other based on their fitness values, separation of distances. The quantity of the resultant force is determined by using the electrostatics laws and the quality of the movement is determined using Newtonian mechanics laws. Proposed Adaptive Charged System Search Algorithm (ACA) has been tested in Standard IEEE 57,118 bus systems \& real power loss has been comparatively reduced with voltage profiles are within the limits.

\section{Objective Function}

\subsection{Active Power Loss}

The objective of the reactive power dispatch problem is to minimize the active power loss and can be defined in equations as follows:

$\mathrm{F}=\mathrm{PL}=\sum_{\mathrm{k} \in \mathrm{Nbr}} \mathrm{g}_{\mathrm{k}}\left(\mathrm{V}_{\mathrm{i}}^{2}+\mathrm{V}_{\mathrm{j}}^{2}-2 \mathrm{~V}_{\mathrm{i}} \mathrm{V}_{\mathrm{j}} \cos \theta_{\mathrm{ij}}\right)$

Where $g_{k}$ : is the conductance of branch between nodes $i$ and $j$, Nbr: is the total number of transmission lines in power systems.

\subsection{Voltage Profile Improvement}

To minimize the voltage deviation in PQ buses, the objective function can be written as:

$\mathrm{F}=\mathrm{PL}+\omega_{\mathrm{v}} \times \mathrm{VD}$

Where $\omega_{\mathrm{v}}$ : is a weighting factor of voltage deviation.

$\mathrm{VD}$ is the voltage deviation given by:

$\mathrm{VD}=\sum_{\mathrm{i}=1}^{\mathrm{Npq}}\left|\mathrm{V}_{\mathrm{i}}-1\right|$

\subsection{Equality Constraint}

The equality constraint of the problem is indicated by the power balance equation as follows: $\mathrm{P}_{\mathrm{G}}=\mathrm{P}_{\mathrm{D}}+\mathrm{P}_{\mathrm{L}}$

Where the total power generation PG has to cover the total power demand PD and the power losses PL.

\subsection{Inequality Constraints}

The inequality constraint implies the limits on components in the power system in addition to the limits created to make sure system security. Upper and lower bounds on the active power of slack bus, and reactive power of generators are written as follows:

$\mathrm{P}_{\text {gslack }}^{\min } \leq \mathrm{P}_{\text {gslack }} \leq \mathrm{P}_{\text {gslack }}^{\max }$ 
$\mathrm{Q}_{\mathrm{gi}}^{\min } \leq \mathrm{Q}_{\mathrm{gi}} \leq \mathrm{Q}_{\mathrm{gi}}^{\max }, \mathrm{i} \in \mathrm{N}_{\mathrm{g}}$

Upper and lower bounds on the bus voltage magnitudes:

$\mathrm{V}_{\mathrm{i}}^{\min } \leq \mathrm{V}_{\mathrm{i}} \leq \mathrm{V}_{\mathrm{i}}^{\max }, \mathrm{i} \in \mathrm{N}$

Upper and lower bounds on the transformers tap ratios:

$\mathrm{T}_{\mathrm{i}}^{\mathrm{min}} \leq \mathrm{T}_{\mathrm{i}} \leq \mathrm{T}_{\mathrm{i}}^{\text {max }}, \mathrm{i} \in \mathrm{N}_{\mathrm{T}}$

Upper and lower bounds on the compensators

$\mathrm{Q}_{\mathrm{c}}^{\min } \leq \mathrm{Q}_{\mathrm{c}} \leq \mathrm{Q}_{\mathrm{C}}^{\max }, \mathrm{i} \in \mathrm{N}_{\mathrm{C}}$

Where $\mathrm{N}$ is the total number of buses, NT is the total number of Transformers; Nc is the total number of shunt reactive compensators.

\section{Adaptive Charged System Search Algorithm (ACA)}

In this section, a new efficient optimization algorithm is established utilizing the aforementioned physics laws, which is called Adaptive Charged System Search Algorithm (ACA). In the Adaptive Charged System Search Algorithm (ACA), each solution candidate X i containing a number of decision variables i.e $\left(X_{i}=\left\{X_{i, j}\right\}\right)$ is considered as a charged particle [34-37]. The charged particle is affected by the electrical fields of the other agents. The quantity of the resultant force is determined by using the electrostatics laws and the quality of the movement is determined using the Newtonian mechanics laws. It seems that an agent with good results must exert a stronger force than the bad ones, so the amount of the charge will be defined considering the objective function value, fit (i). In order to introduce ACA, the following rules are developed: Rule 1 Many of the natural evolution algorithms maintain a population of solutions which are evolved through random alterations and selection. Similarly, ACA considers a number of Charged Particles (CP). Each $\mathrm{CP}$ has a magnitude of charge (qi) and as a result creates an electrical field around its space. The magnitude of the charge is defined considering the quality of its solution, as follows:

$q i=\frac{\text { fit (i)-fitworst }}{\text { fitbest-fitworst }}, i=1,2, \ldots, N$,

where, fitbest and fitworst are the so far best and the worst fitness of all particles; fit (i) represents the objective function value or the fitness of the agent $i$; and $\mathrm{N}$ is the total number of CPs. The separation distance rij between two charged particles is defined as follows:

$r_{i j}=\frac{\left\|x_{i}-x_{j}\right\|}{\left\|\frac{\left(x_{i}+x_{j}\right)}{2}-x_{\text {best }}\right\|+\varepsilon}$,

Where $\mathrm{Xi}$ and $\mathrm{Xj}$ are the positions of the $\mathrm{i}$ th and $\mathrm{j}$ th CPs, Xbest is the position of the best current $\mathrm{CP}$, and $\varepsilon$ is a small positive number to avoid singularities.

Rule 2 the initial positions of CPs are determined randomly in the search space

$x_{i, j}^{(0)}=x_{i, \text { min }}+$ rand $\cdot\left(x_{i, \max }-x_{i, \min }\right), i=1,2, \ldots, n$ 
where $x_{i, j}^{(0)}$ determines the initial value of the $i$ th variable for the $j$ th $C P ; x_{i, \min }$ and $x_{i, \max }$ are the minimum and the maximum allowable values for the $i$ th variable; rand is a random number in the interval $[0,1]$; and $\mathrm{n}$ is the number of variables. The initial velocities of charged particles are zero

$v_{i, j}^{(0)}=0, i=1,2, \ldots, n$.

Rule 3 Three conditions could be considered related to the kind of the attractive forces: Any CP can affect another one; i.e., a bad CP can affect a good one and vice versa $\left(p_{i j}=1\right)$. A CP can attract another if its electric charge amount (fitness with revise relation in minimizing problems) is better than other. In other words, a good CP attracts a bad CP:

$\mathrm{p}_{\mathrm{ij}}= \begin{cases}1 & \text { fit }(\mathrm{j})>\operatorname{fit}(\mathrm{i}), \\ 0 & \text { else }\end{cases}$

All good CPs can attract bad CPs and only some of bad agents attract good agents, considering following probability function:

$\mathrm{p}_{\mathrm{ij}}=\left\{\begin{array}{l}1 \frac{\mathrm{fit}(\mathrm{i})-\mathrm{fitbest}}{\mathrm{fit}(\mathrm{j})-\mathrm{fit}(\mathrm{i})}>\operatorname{randvfit}(\mathrm{j})>\mathrm{fit}(\mathrm{i}) \\ 0 \text { else }\end{array}\right.$

According to the above conditions, when a good agent attracts a bad one, the exploitation ability for the algorithm is provided, and vice versa if a bad CP attracts a good CP, the exploration is provided. When a CP moves toward a good agent it improves its performance, and so the selfadaptation principle is guaranteed. Moving a good CP toward a bad one may cause losing the previous good solution or at least increasing the computational cost to find a good solution. To resolve this problem, a memory which saves the best-so-far solution can be considered. Therefore, it seems that the third kind of the above conditions is the best rule because of providing strong exploration ability and an efficient exploitation.

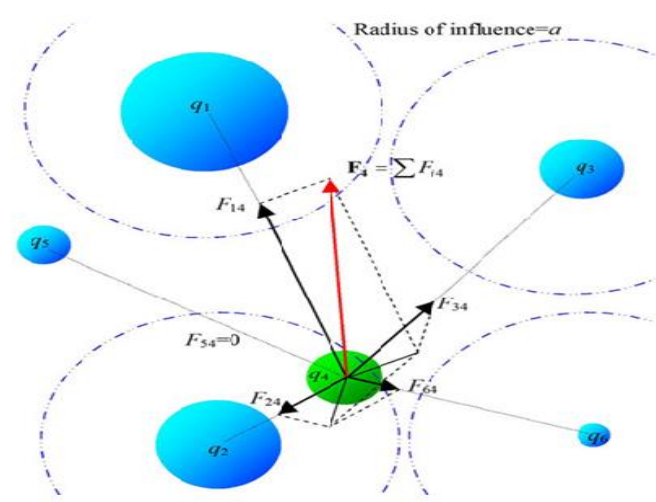

Figure 1: Determination of the resultant electrical force acting on a $\mathrm{CP}$

Rule 4 the value of the resultant electrical force acting on a $\mathrm{CP}$ is

$F_{j}=q_{j} \sum_{i, i \neq j}\left(\frac{q i}{a^{3}} r_{i j} \cdot i_{1}+\frac{q i}{r_{i j}^{2}} \cdot i_{2}\right) p_{i j}\left(X_{i}-X_{j}\right),\left\{\begin{array}{l}j=1,2, \ldots, N \\ i_{1}=1, i_{2}=0 \Leftrightarrow r_{i j}<a \\ i_{1}=0, i_{2}=1 \Leftrightarrow r_{i j} \geq a\end{array}\right.$ 
Where $\mathrm{Fj}$ is the resultant force acting on the $\mathrm{j}$ th $\mathrm{CP}$, as illustrated in Fig. 1.

In this algorithm, each $\mathrm{CP}$ is considered as a charged sphere with radius a, which has a uniform volume charge density. In this paper, the magnitude of set to unity; however, for more complex examples, the appropriate value for a must be defined considering the size of the search space. One can utilize the following equation as a general formula:

$a=0.10 X \max \left(\left\{x_{i, \max }-x_{i, \min } \mid i=1,2, \ldots, n\right\}\right)$.

According to this rule, in the first iteration where the agents are far from each other the magnitude of the resultant force acting on a $\mathrm{CP}$ is inversely proportional to the square of the separation between the particles. Thus the exploration power in this condition is high because of performing more searches in the early iterations. It is necessary to increase the exploitation of the algorithm and to decrease the exploration gradually. After a number of searches where CPs are collected in a small space and the separation between the CPs becomes small, say 0.1, then the resultant force becomes proportional to the separation distance of the particles instead of being inversely proportional to the square of the separation distance. Therefore, the parameter a separates the global search phase and the local search phase, i.e., when majority of the agents are collected in a space with radius a, the global search is finished and the optimizing process is continued by improving the previous results, and thus the local search starts. Besides, using these principles controls the balance between the exploration and the exploitation. It should be noted that this rule considers the competition step of the algorithm. Since the resultant force is proportional to the magnitude of the charge, a better fitness (great qi) can create a stronger attracting force, so the tendency to move toward a good CP becomes more than toward a bad particle.

Rule 5 the new position and velocity of each $\mathrm{CP}$ is

$\mathrm{X}_{\mathrm{j}, \text { new }}=\operatorname{rand}_{\mathrm{j} 1} \cdot \mathrm{k}_{\mathrm{a}} \cdot \frac{\mathrm{F}_{\mathrm{j}}}{\mathrm{m}_{\mathrm{j}}} \cdot \Delta \mathrm{t}^{2}+\operatorname{rand}_{\mathrm{j} 2} \cdot \mathrm{k}_{\mathrm{v}} \cdot \mathrm{V}_{\mathrm{j}, \mathrm{old}} \cdot \Delta \mathrm{t}+\mathrm{X}_{\mathrm{j}, \mathrm{old}}$,

$\mathrm{V}_{\mathrm{j}, \text { new }}=\frac{\mathrm{X}_{\mathrm{j}, \text { new }}-\mathrm{X}_{\mathrm{j}, \mathrm{old}}}{\Delta \mathrm{t}}$,

Where $\mathrm{ka}$ is the acceleration coefficient; $\mathrm{kv}$ is the velocity coefficient to control the influence of the previous velocity; and rand $\mathrm{j} 1$ and rand $\mathrm{j} 2$ are two random numbers uniformly distributed in the range of $(0,1)$. Here, $\mathrm{m} \mathrm{j}$ is the mass of the $\mathrm{jth} \mathrm{CP}$ which is equal to $\mathrm{qj} \cdot \Delta$ tis the time step and is set to unity. The effect of the pervious velocity and the resultant force acting on a $\mathrm{CP}$ can be decreased or increased based on the values of the kv and ka, respectively. Excessive search in the early iterations may improve the exploration ability; however, it must be decreased gradually, as described before. Since ka is the parameter related to the attracting forces, selecting a large value for this parameter may cause a fast convergence and vice versa a small value can increase the computational time. In fact ka $t$ is a control parameter of the exploitation. Therefore, choosing an incremental function can improve the performance of the algorithm. Also, the direction of the pervious velocity of a $\mathrm{CP}$ is not necessarily the same as the resultant force. Thus, it can be concluded that the velocity coefficient $\mathrm{kv}$ controls the exploration process and therefore a decreasing function can be selected. Thus, $\mathrm{kv}$ and $\mathrm{ka}$ are defined as,

$\mathrm{k}_{\mathrm{v}}=0.5\left(1-\right.$ iter $/$ iter $\left._{\max }\right), \mathrm{k}_{\mathrm{a}}=0.5\left(1+{\left.\text { iter } / \text { iter }_{\max }\right)}\right.$ 
Where iter is the actual iteration number and itermax is the maximum number of iterations. With this equation, $\mathrm{kv}$ decreases linearly to zero while ka increases to one when the number of iterations rises. In this way, the balance between the exploration and the fast rate of convergence is saved. Considering the values of these parameters, Eqs. (21) and (22) can be rewritten as

$$
\begin{aligned}
& \mathrm{X}_{\mathrm{j}, \text { new }}=0.5 \mathrm{rand}_{\mathrm{j} 1} \cdot\left(1+\mathrm{iter} / \text { iter }_{\text {max }}\right) \cdot \sum_{\mathrm{i}, \mathrm{i} \neq \mathrm{j}}\left(\frac{\mathrm{q} \mathrm{i}}{\mathrm{a}^{3}} \mathrm{r}_{\mathrm{ij}} \cdot \mathrm{i}_{1}+\frac{\mathrm{qi}}{\mathrm{r}_{\mathrm{ij}}^{2}} \cdot \mathrm{i}_{2}\right) \mathrm{p}_{\mathrm{ij}}\left(\mathrm{X}_{\mathrm{i}}-\mathrm{x}_{\mathrm{j}}\right)+0.5 \mathrm{rand}_{\mathrm{j} 2} \cdot \\
& \left(1+\mathrm{iter} / \text { iter }_{\text {max }}\right) \cdot \mathrm{V}_{\mathrm{j}, \text { old }}+\mathrm{X}_{\mathrm{j}, \text { old }} \\
& \mathrm{V}_{\mathrm{j}, \text { new }}=\mathrm{X}_{\mathrm{j}, \text { new }}-\mathrm{X}_{\mathrm{j}, \text { old, }}
\end{aligned}
$$

Figure 5 illustrates the motion of a CP to its new position using this rule. The rules 5 and 6 provide the cooperation step of the CPs, where agents collaborate with each other by information transferring.

Rule 6 considering a memory which saves the best $\mathrm{CP}$ vectors and their related objective function values can improve the algorithm performance without increasing the computational cost. To fulfill this aim, Charged Memory (CM) is utilized to save a number of the best so far solutions. In this paper, the size of the CM (i.e. CMS) is taken as N/4. Another benefit of the CM consists of utilizing this memory to guide the current CPs. In other words, the vectors stored in the CM can attract current CPs according to Eq. (16). Instead, it is assumed that the same number of the current worst particles cannot attract the others.

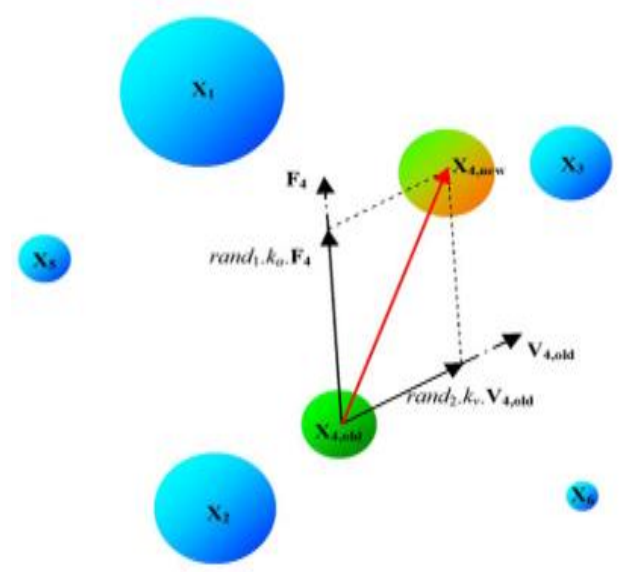

Figure 2: The movement of a CP to the new position

Rule 7 There are two major problems in relation to many meta-heuristic algorithms; the first problem is the balance between exploration and exploitation in the beginning, during, and at the end of the search, and the second is how to deal with an agent violating the limits of the variables. The first problem is solved naturally through the application of above-stated rules; however, in order to solve the second problem, one of the simplest approaches is utilizing the nearest limit values for the violated variable. Alternatively, one can force the violating particle to return to its previous position, or one can reduce the maximum value of the velocity to allow fewer particles to violate the variable boundaries. Although these approaches are simple, they are not sufficiently efficient and may lead to reduce the exploration of the search space. This problem has previously been addressed and solved using the harmony search-based handling 
approach [38]. According to this mechanism, any component of the solution vector violating the variable boundaries can be regenerated from the CM as

$\mathrm{x}_{\mathrm{i}, \mathrm{j}}=\left\{\begin{array}{l}\text { w.p. } \mathrm{CMCR} \\ \text { w.p. }(1-\mathrm{CMCR})\end{array}\right.$

Subject to

$\Rightarrow$ Select a new value for a variable from $\mathrm{CM}$

$\Rightarrow$ w.p (1-PAR) do nothing

$\Rightarrow$ w.p.PAR choose a neighbouring value

$\Rightarrow$ select a new value

where "w.p." is the abbreviation for "with the probability"; xij is the $\mathrm{i}$ th component of the CP $\mathrm{j}$; The CMCR (the Charged Memory Considering Rate) varying between 0 and 1 sets the rate of choosing a value in the new vector from the historic values stored in the CM, and (1 CMCR)sets the rate of randomly choosing one value from the possible range of values. The pitch adjusting process is performed only after a value is chosen from CM. The value (1-PAR) sets the rate of doing nothing, and PAR sets the rate of choosing a value from neighbouring the best CP.

Rule 8 the terminating criterion is one of the following:

Maximum number of iterations: the optimization process is terminated after a fixed number of iterations, for example, 1,000 iterations. Number of iterations without improvement: the optimization process is terminated after some fixed number of iterations without any improvement. Minimum objective function error: the difference between the values of the best objective function and the global optimum is less than a pre-fixed anticipated threshold. Difference between the best and the worst CPs: the optimization process is stopped if the difference between the objective values of the best and the worst CPs becomes less than a specified accuracy. Maximum distance of CPs: the maximum distance between CPs is less than a pre-fixed value. Now we can establish a new optimization algorithm utilizing the above rules.

\section{Adaptive Charged System Search Algorithm (ACA) For Solving Optimal Power Problem}

Level 1: Initialization

Step 1: Initialization. Initialize ACA algorithm parameters; Initialize an array of Charged Particles with random positions and their associated velocities (Rules 1 and 2).

Step 2: CP ranking. Evaluate the values of the fitness function for the CPs, compare with each other and sort increasingly.

Step 3: CM creation. Store the CMS number of the first CPs and their related values of the objective function in the CM.

Level 2: Search

Step 1: Attracting force determination. Determine the probability of moving each CP toward others (Rule 3), and calculate the attracting force vector for each CP (Rule 4).

Step 2: Solution construction. Move each CP to the new position and find the velocities (Rule 5). Step 3: CP position correction. If each CP exits from the allowable search space, correct its position using Rule 7. 
Step 4: CP ranking. Evaluate and compare the values of the objective function for the new CPs, and sort them increasingly.

Step 5: CM updating. If some new $\mathrm{CP}$ vectors are better than the worst ones in the $\mathrm{CM}$, include the better vectors in the CM and exclude the worst ones from the CM (Rule 6)

Level 3: Terminating criterion controlling

Repeat search level steps until a terminating criterion is satisfied (Rule 8).

\section{Simulation Results}

At first Adaptive Charged System Search Algorithm (ACA) has been tested in standard IEEE-57 bus power system. The reactive power compensation buses are 18, 25 and 53. Bus 2, 3, 6, 8, 9 and 12 are PV buses and bus 1 is selected as slack-bus. The system variable limits are given in Table 1.

The preliminary conditions for the IEEE-57 bus power system are given as follows:

$\mathrm{P}_{\text {load }}=12.118$ p.u. Q $_{\text {load }}=3.074$ p.u.

The total initial generations and power losses are obtained as follows:

$\sum P_{G}=12.462$ p.u. $\sum Q_{G}=3.3152$ p.u.

$\mathrm{P}_{\text {loss }}=0.25848$ p.u. $\mathrm{Q}_{\text {loss }}=-1.2062$ p.u.

Table 2 shows the various system control variables i.e. generator bus voltages, shunt capacitances and transformer tap settings obtained after optimization which are within the acceptable limits. In Table 3, shows the comparison of optimum results obtained from proposed methods with other optimization techniques. These results indicate the robustness of proposed approaches for providing better optimal solution in case of IEEE-57 bus system.

Table 1: Variable Limits

\begin{tabular}{|l|l|l|l|l|l|l|l|}
\hline Reactive Power Generation Limits \\
\hline Bus no & 1 & 2 & 3 & 6 & 8 & 9 & 12 \\
\hline Qgmin & -1.4 & -.015 & -.02 & -0.04 & -1.3 & -0.03 & -0.4 \\
\hline Qgmax & 1 & 0.3 & 0.4 & 0.21 & 1 & 0.04 & 1.50 \\
\hline Voltage And Tap Setting Limits \\
\hline vgmin & Vgmax & vpqmin & Vpqmax & tkmin & tkmax \\
\hline 0.9 & 1.0 & 0.91 & 1.05 & 0.9 & 1.0 \\
\hline \hline Shunt Capacitor Limits \\
\hline Bus no & 18 & 25 & 53 \\
\hline Qcmin & 0 & 0 & 0 \\
\hline Qcmax & 10 & 5.2 & 6.1 \\
\hline
\end{tabular}

Table 2: Control variables obtained after optimization

\begin{tabular}{|l|l|}
\hline Control Variables & ACA \\
\hline V1 & 1.10 \\
\hline V2 & 1.038 \\
\hline V3 & 1.037 \\
\hline V6 & 1.026 \\
\hline V8 & 1.025 \\
\hline V9 & 1.004 \\
\hline
\end{tabular}




\begin{tabular}{|l|l|}
\hline V12 & 1.010 \\
\hline Qc18 & 0.0663 \\
\hline Qc25 & 0.200 \\
\hline Qc53 & 0.0472 \\
\hline T4-18 & 1.001 \\
\hline T21-20 & 1.049 \\
\hline T24-25 & 0.868 \\
\hline T24-26 & 0.877 \\
\hline T7-29 & 1.056 \\
\hline T34-32 & 0.875 \\
\hline T11-41 & 1.014 \\
\hline T15-45 & 1.030 \\
\hline T14-46 & 0.910 \\
\hline T10-51 & 1.020 \\
\hline T13-49 & 1.060 \\
\hline T11-43 & 0.910 \\
\hline T40-56 & 0.900 \\
\hline T39-57 & 0.950 \\
\hline T9-55 & 0.950 \\
\hline
\end{tabular}

Table 3: Comparison results

\begin{tabular}{|l|l|l|l|l|}
\hline S.No. & Optimization Algorithm & Finest Solution & Poorest Solution & Normal Solution \\
\hline 1 & NLP [39] & 0.25902 & 0.30854 & 0.27858 \\
\hline 2 & CGA [39] & 0.25244 & 0.27507 & 0.26293 \\
\hline 3 & AGA [39] & 0.24564 & 0.26671 & 0.25127 \\
\hline 4 & PSO-w [39] & 0.24270 & 0.26152 & 0.24725 \\
\hline 5 & PSO-cf [39] & 0.24280 & 0.26032 & 0.24698 \\
\hline 6 & CLPSO [39] & 0.24515 & 0.24780 & 0.24673 \\
\hline 7 & SPSO-07 [39] & 0.24430 & 0.25457 & 0.24752 \\
\hline 8 & L-DE [39] & 0.27812 & 0.41909 & 0.33177 \\
\hline 9 & L-SACP-DE [39] & 0.27915 & 0.36978 & 0.31032 \\
\hline 10 & L-SaDE [39] & 0.24267 & 0.24391 & 0.24311 \\
\hline 11 & SOA [39] & 0.24265 & 0.24280 & 0.24270 \\
\hline 12 & LM [40] & 0.2484 & 0.2922 & 0.2641 \\
\hline 13 & MBEP1 [40] & 0.2474 & 0.2848 & 0.2643 \\
\hline 14 & MBEP2 [40] & 0.2482 & 0.283 & 0.2592 \\
\hline 15 & BES100 [40] & 0.2438 & 0.263 & 0.2541 \\
\hline 16 & BES200 [40] & 0.3417 & 0.2486 & 0.2443 \\
\hline 17 & Proposed ACA & 0.22058 & 0.23012 & 0.22236 \\
\hline & & & & \\
\hline
\end{tabular}

Then Adaptive Charged System Search Algorithm (ACA) has been tested in standard IEEE 118bus test system [41].The system has 54 generator buses, 64 load buses, 186 branches and 9 of them are with the tap setting transformers. The limits of voltage on generator buses are $0.95-1.1$ per-unit., and on load buses are $0.95-1.05$ per-unit. The limit of transformer rate is $0.9-1.1$, with 
the changes step of 0.025 . The limitations of reactive power source are listed in Table 4 , with the change in step of 0.01 .

Table 4: Limitation of reactive power sources

\begin{tabular}{|l|l|l|l|l|l|l|l|}
\hline BUS & 5 & 34 & 37 & 44 & 45 & 46 & 48 \\
\hline QCMAX & 0 & 14 & 0 & 10 & 10 & 10 & 15 \\
\hline QCMIN & -40 & 0 & -25 & 0 & 0 & 0 & 0 \\
\hline BUS & 74 & 79 & 82 & 83 & 105 & 107 & 110 \\
\hline QCMAX & 12 & 20 & 20 & 10 & 20 & 6 & 6 \\
\hline QCMIN & 0 & 0 & 0 & 0 & 0 & 0 & 0 \\
\hline
\end{tabular}

The statistical comparison results of 50 trial runs have been list in Table 5 and the results clearly show the better performance of proposed Adaptive Charged System Search Algorithm (ACA) in reducing the real power loss.

Table 5: Comparison results

\begin{tabular}{|l|l|l|l|l|}
\hline Active power loss (MW) & $\begin{array}{l}\text { BBO } \\
{[\mathbf{4 2}]}\end{array}$ & $\begin{array}{l}\text { ILSBBO/ } \\
\text { strategy1 } \\
{[\mathbf{4 2}]}\end{array}$ & $\begin{array}{l}\text { ILSBBO/ } \\
\text { strategy1 } \\
{[\mathbf{4 2}]}\end{array}$ & $\begin{array}{l}\text { Proposed } \\
\text { ACA }\end{array}$ \\
\hline Min & 128.77 & 126.98 & 124.78 & 116.04 \\
\hline Max & 132.64 & 137.34 & 132.39 & 120.98 \\
\hline Average & 130.21 & 130.37 & 129.22 & 118.76 \\
\hline
\end{tabular}

\section{Conclusion}

In this paper a novel approach Adaptive Charged System Search Algorithm (ACA) used to solve optimal reactive power problem, by considering various generator constraints. To handle the mixed variables a flexible representation scheme was proposed. Adaptive Charged System Search Algorithm (ACA) is a multi-agent approach in which each agent is a Charged Particle (CP) \& they affect each other based on their fitness values, separation of distances. The quantity of the resultant force is determined by using the electrostatics laws and the quality of the movement is determined using Newtonian mechanics laws. Proposed Adaptive Charged System Search Algorithm (ACA) has been tested in Standard IEEE 57,118 bus systems \& real power loss has been comparatively reduced with voltage profiles are within the limits.

\section{References}

[1] O.Alsac,and B. Scott, “Optimal load flow with steady state security”,IEEE Transaction. PAS 1973, pp. 745-751.

[2] Lee K Y ,Paru Y M , Oritz J L -A united approach to optimal real and reactive power dispatch , IEEE Transactions on power Apparatus and systems 1985: PAS-104 : 1147-1153

[3] A.Monticelli , M .V.F Pereira, and S. Granville, "Security constrained optimal power flow with post contingency corrective rescheduling", IEEE Transactions on Power Systems :PWRS-2, No. 1, pp.175-182.,1987.

[4] DeebN ,Shahidehpur S.M ,Linear reactive power optimization in a large power network using the decomposition approach. IEEE Transactions on power system 1990: 5(2) : 428-435 
[5] E. Hobson ,'Network consrained reactive power control using linear programming, ' IEEE Transactions on power systems PAS -99 (4) ,pp 868=877, 1980

[6] K.Y Lee, Y.M Park, and J.L Oritz, "Fuel -cost optimization for both real and reactive power dispatches", IEE Proc; 131C,(3), pp.85-93.

[7] M.K. Mangoli, and K.Y. Lee, "Optimal real and reactive power control using linear programming”,Electr.PowerSyst.Res, Vol.26, pp.1-10,1993.

[8] C.A. Canizares , A.C.Z.de Souza and V.H. Quintana, " Comparison of performance indices for detection of proximity to voltage collapse ," vol. 11. no.3 , pp.1441-1450, Aug 1996.

[9] S.R.Paranjothi ,andK.Anburaja, "Optimal power flow using refined genetic algorithm", Electr.PowerCompon.Syst, Vol. 30, 1055-1063,2002.

[10] D. Devaraj, and B. Yeganarayana, "Genetic algorithm based optimal power flow for security enhancement", IEE proc-Generation.Transmission and. Distribution; 152, 6 November 2005.

[11] Berizzi, C. Bovo, M. Merlo, and M. Delfanti, "A ga approach to compare orpf objective functions including secondary voltage regulation," Electric Power Systems Research, vol. 84, no. 1, pp. 187 $-194,2012$.

[12] C.-F. Yang, G. G. Lai, C.-H. Lee, C.-T. Su, and G. W. Chang, "Optimal setting of reactive compensation devices with an improved voltage stability index for voltage stability enhancement," International Journal of Electrical Power and Energy Systems, vol. 37, no. 1, pp. $50-57,2012$.

[13] P. Roy, S. Ghoshal, and S. Thakur, "Optimal var control for improvements in voltage profiles and for real power loss minimization using biogeography based optimization," International Journal of Electrical Power and Energy Systems, vol. 43, no. 1, pp. 830 - 838, 2012.

[14] B. Venkatesh, G. Sadasivam, and M. Khan, "A new optimal reactive power scheduling method for loss minimization and voltage stability margin maximization using successive multi-objective fuzzy lp technique," IEEE Transactions on Power Systems, vol. 15, no. 2, pp. 844 - 851, may 2000.

[15] W. Yan, S. Lu, and D. Yu, "A novel optimal reactive power dispatch method based on an improved hybrid evolutionary programming technique," IEEE Transactions on Power Systems, vol. 19, no. 2, pp. 913 - 918, may 2004.

[16] W. Yan, F. Liu, C. Chung, and K. Wong, "A hybrid genetic algorithminterior point method for optimal reactive power flow," IEEE Transactions on Power Systems, vol. 21, no. 3, pp. 1163 1169, aug. 2006.

[17] J. Yu, W. Yan, W. Li, C. Chung, and K. Wong, "An unfixed piecewiseoptimal reactive powerflow model and its algorithm for ac-dc systems," IEEE Transactions on Power Systems, vol. 23, no. 1, pp. $170-176$, feb. 2008.

[18] F. Capitanescu, "Assessing reactive power reserves with respect to operating constraints and voltage stability," IEEE Transactions on Power Systems, vol. 26, no. 4, pp. 2224-2234, nov. 2011.

[19] Z. Hu, X. Wang, and G. Taylor, "Stochastic optimal reactive power dispatch: Formulation and solution method," International Journal of Electrical Power and Energy Systems, vol. 32, no. 6, pp. $615-621,2010$.

[20] Kargarian, M. Raoofat, and M. Mohammadi, "Probabilistic reactive power procurement in hybrid electricity markets with uncertain loads," Electric Power Systems Research, vol. 82, no. 1, pp. 68 $-80,2012$.

[21] D. Karaboga, "An idea based on honey bee swarm for numerical optimization," Tech. Rep. TR06, Erciyes Univ. Press, Erciyes, 2005.

[22] D. Karaboga and B. Basturk, "A powerful and efficient algorithm fornumerical function optimization: Artificial bee colony (ABC) algorithm," Journal of Global Optimization, Vol. 39, No. 3, pp. 459-471, 2007.

[23] D. Karaboga and B. Basturk, "On the performance of artificial beecolony (ABC) algorithm," Applied Soft computing, Vol. 8, pp. 687-697, 2008. 
[24] D. Karaboga and B. Akay, "A comparative study of artificial Beecolony algorithm," Applied Mathematics and Computation, Vol. 214,No. 1, pp. 108-132, 2009.

[25] D. Whitley, “A genetic Algorithm tutorial," Statistics and Computing, Vol. 4, pp. 65-85, 1994.

[26] D. Karaboga and B. Akay, "artificial bee colony (abc) algorithm ontraining artificial neural networks 15th IEEE Signal Processing andCommunications Applications, pp.1-4, 2007.

[27] S. K. Udgata, S. L. Sabat and S. Mini, "Sensor deployment in irregularterrain using artificial bee colony algorithm," IEEE Congress on Nature\& Biologically Inspired Computing, pp. 1309-1314, 2009.

[28] B. Akay and D. Karaboga, "Artificial bee colony algorithm for largescaleproblems and engineering design optimization," Journal ofIntelligent Manufacturing, Vol. 23, No. 4, pp. 1001$1014,2010$.

[29] B. Alatas, "Chaotic bee colony algorithm for global numericaloptimization," Expert Systems with Applications, Vol. 37, pp. 5682-5687, 2010.

[30] G. Zhu and S. Kwong, "Gbest-guided artificial bee colony algorithm fornumerical function optimization,” Applied Mathematics andComputation, Vol. 217, pp. 3166-3173, 2010.

[31] Banharnsakun, T. Achalakul and B. Sirinaovakul, "The best-so-farselection in artificial bee colony algorithm," Applied Soft Computing,Vol. 11, No. 2, pp. 2888-2901, 2011.

[32] D. Karaboga and B. Gorkemli, "A combinatorial artificial bee colonyalgorithm for traveling salesman problem," International Symposium onInnovation in Intelligent Systems and Applications (INISTA), pp. 50-53, 2011.

[33] W. Gao and S. Liu, "A modified artificial bee colony algorithm,"Computers \& Operations Research, Vol. 39. pp. 687-697, 2012.

[34] Kaveh, A., and Talatahari, S. (2010 a). A novel heuristic optimization method: charged system search. Acta Mechanica, vol. 213, no. 3-4, pp. 267- 289.

[35] Kaveh, A., and Talatahari, S. (2010b). Optimal design of skeletal structures via the charged system search algorithm. Structural and Multidisciplinary Optimization, vol. 41, no. 6, pp. 893911.

[36] Kaveh, A., and Laknejadi, K. (2011a). A novel hybrid charge system search and particle swarm optimization method for multi-objective optimization. Expert Systems with Applications, vol. 38, no. 12 , pp. $15475-15488$.

[37] Kaveh, A., and Talatahari S. (2011b). An enhanced charged system search for configuration optimization using the concept of fields of forces. Structural and Multidisciplinary Optimization, vol. 43 , no. 3 , pp. 339-351.

[38] Kaveh, A., Talatahari, S.: Particle swarm optimizer, ant colony strategy and harmony search scheme hybridized for optimization of truss structures. Comput. Struct. 87(5-6), 267-283 (2009)

[39] Chaohua Dai, Weirong Chen, Yunfang Zhu, and Xuexia Zhang, "Seeker optimization algorithm for optimal reactive power dispatch,” IEEE Trans. Power Systems, Vol. 24, No. 3, August 2009, pp. 1218-1231.

[40] J. R. Gomes and 0. R. Saavedra, "Optimal reactive power dispatch using evolutionary computation: Extended algorithms," IEE Proc.-Gener. Transm. Distrib.. Vol. 146, No. 6. Nov. 1999.

[41] IEEE, "The IEEE 30-bus test system and the IEEE 118-test system", (1993), http://www.ee.washington.edu/trsearch/pstca/.

[42] Jiangtao Cao, Fuli Wang and Ping Li, "An Improved Biogeography-based Optimization Algorithm for Optimal Reactive Power Flow" International Journal of Control and Automation Vol.7, No.3 (2014), pp.161-176.

*Corresponding author.

E-mail address: gklenin@ gmail.com 